\title{
Successful Management of Takayasu's Arteritis with Pulmonary Hypertension in Pregnancy: A Rare Case
}

\section{Wiryawan Permadi, Dani Setiawan, Muhammad Alamsyah Aziz*, Yanuarman, Anita D. Anwar, Firman Fuad Wirakusumah}

Obstetrics and Gynecology Department, Faculty of Medicine, Padjadjaran University, Hasan Sadikin Hospital, Bandung, Indonesia

Email: *alamsya ha ziz9119@gmail.com

How to cite this paper: Permadi, W., Setiawan, D., Alamsyah Aziz, M., Yanuarman, Anwar, A.D. and Wirakusumah, F.F. (2019) Successful Management of Takayasu's Arteritis with Pulmonary Hypertension in Pregnancy: A Rare Case. Open Journal of Obstetrics and Gynecology, 9, 1151-1160. https://doi.org/10.4236/ojog.2019.98111

Received: June 3, 2019

Accepted: August 12, 2019

Published: August 15, 2019

Copyright $\odot 2019$ by author(s) and Scientific Research Publishing Inc. This work is licensed under the Creative Commons Attribution International License (CC BY 4.0).

http://creativecommons.org/licenses/by/4.0/ c) (i) Open Access

\begin{abstract}
Introduction: Takayasu's arteritis (TA) is a rare systemic, chronic inflammatory, progressive, idiopathic disease of aorta and its main branches. Takayasu's arteritis causes narrowing, occlusion and aneurysm of arteries. The etiology of TA is still unknown. It may be autoimmune or genetic in origin or infective diseases. It is commonly found in Asia and oriental countries. Worldwide annual incidence is $1.2-2.6$ cases/million. Women are affected in $80 \%-90 \%$ of cases with age of onset below 40 years. TA does not worsen or improve with pregnancy but has adverse effect on pregnancy in the form of abortion, Intrauterine fetal death, superimposed preeclampsia, Intrauterine growth restriction, abruption and congestive heart failure. Because the disease is common in women of childbearing age, management of pregnancy in these patients becomes important; however optimal management for pregnant patients with this disease has not yet been established. Due to the manifold cardiovascular complications that can occur in the course of the disease, management of pregnancies in TA patients is a challenge for the clinician. An interdisciplinary collaboration of obstetrician, rheumatologist, cardiologist and anaesthetist is necessary to improve maternal and fetal prognosis. This was the first reported case of TA in pregnancy in Hasan Sadikin Hospital with superimposed preeclampsia and pulmonary hypertension. Materials and Methods: The patient, G1P0A0 was diagnosed as TA since one year ago, and when the patient was pregnant, the patient routinely came to obstetric and rheumatology clinics. Angiographic examination showed dilatation of aorta ascendant, narrowing of aorta descendent at 8 thoracal vertebrae, and arcus aorta, abdominal aorta and the branches were without abnormalities that lead to type IIb TA. On physical examination blood pressure was $200 / 100 \mathrm{mmHg}$
\end{abstract}


on the right arm, and 140/100 $\mathrm{mm} \mathrm{Hg}$ on the left arm, right hand pulse 120 $\mathrm{x} / \mathrm{m}$, left hand pulse $113 \mathrm{x} / \mathrm{m}$, respiration rate $20 \mathrm{x} / \mathrm{m}$, temperature $36^{\circ} \mathrm{C}$. Laboratory values showed Elevated C-reactive protein $6.8 \mathrm{Mg} / \mathrm{dl}$, anemia hemoglobin $10.5 \mathrm{~g} / \mathrm{dL}$, elevated rate of sedimentation of blood $36 \mathrm{~mm} /$ hours, and proteinuria +2 . The results of other examinations: Glucose, Ureum, Creatinine, GOT, GPT and electrolytes were in normal limits. Thoracal examination/rontgen showed revealed cardiomegaly. Echocardiogram at $20-21$ weeks gestational age showed an ejection fraction of 55\%, hypertensive heart disease and pulmonal hypertension. The ultrasound examination at $36-37$ weeks' gestation showed a 2066 g estimated weight (IUGR simetris). Doppler of the umbilical artery showed a resistance index (RI) of 0.49 , pulsatility index (PI) 0.70 with a positive end diastolic flow (EDF). Doppler of the median cerebry media artery showed a resistance index (RI) of 0.72 , pulsatility index (PI) 1.26. Amniotic Fluid Index 11, $43 \mathrm{~cm}$, Placenta anterior. The pregnancy was controlled tightly in our clinic. During pregnancy in the first trimester, the patient got methylprednisolone $1 \times 4 \mathrm{mg}$, Azathioprin $1 \times 50 \mathrm{mg}$, folic acid $1 \times 1 \mathrm{mg}$. Additional therapy at second trimester were calcium $1000 \mathrm{mg}$, multivitamin $1 \mathrm{x} /$ day, methyldopa $3 \times 250 \mathrm{mg}$ and Acetylsalicylic acid $1 \times 80$ mg. She was scheduled for a cesarean section at $37-38$ weeks of pregnancy. Results: According to the American College of Rheumatology (ACR) 1990, our patient fulfilled 4 of 6 TA criteria: age $<40$ years, decreased pulsation of left brachial arteries, systolic pressure difference of $50 \mathrm{mmHg}$ between arm, and the arteriographic examination showed narrowing of aorta descendent at 8 thoracal vertebra. She was in stage 2 a because she had hypertension, without retinopathy, aneurysm and aortic insufficiency. The patient was monitored with multidisciplinary approach along with the obstetrician, rheumatologist and cardiologist. During antenatal period they followed up periodically with a very strict BP monitoring and fetal growth monitoring. Blood Pressure control was of importance as increase can cause rupture of aneurysms and falls in Blood Pressure could lead to cerebral ischemia in the mother. The risk of fetal death is greatest in the third trimester, especially in those with uncontrolled hypertension. Complication during pregnancy is chronic hypertension superimposed preeclampsia, symmetric IUGR, pulmonal hypertension and hypertension heart disease. The Hypertension may be due to decreased elasticity and narrowing of aorta and abnormal function of carotid and aortic sinus baroreceptor and symmetric IUGR may be impaired by placental blood flow. The mode of delivery in patients with TA is determined by the hemodynamic status of the mother and for obstetrical indications. The patient was scheduled for cesarean section at aterm gestation age, but as 36 weeks she got parturient and emergencies caesarean section was done with epidural anaesthesia by bupivacaine followed by intensive care afterwards. The baby was born with 2180 grams birth weight, body length 44 cm, Apgar 1' 7, 5' 9. Fetal and maternal conditions were good. Conclusions: The management of TA in pregnancy is still a challenge. A multidisciplinary team involving obstetrician, cardiologist, rheumatologist and anaesthetist is 
absolutely needed to get an optimal development of the pregnancy. The risk of complication on the mother and fetus might occur any time. Adequately controlled blood pressure and fetal monitoring might result for better outcome. Birth delivery (pervaginam or perabdominal) is still a problem according to obstetrical condition, general condition of the mother and other additional factors. Careful assessment, treatment of TA complication, and regular antenatal follow-up improve maternal and fetal outcome.

\section{Keywords}

Takayasu's Arthritis, Pulmonary Hypertension, Pregnancy

\section{Introduction}

Takayasu's arteritis (TA) is a rare, systemic, chronic inflammatory, progressive, idiopathic disease of aorta and its main branches [1] [2]. Takayasu's arteritis causes narrowing, occlusion and aneurysm of arteries [2]. The etiology of TA is still unknown. It may be autoimmune or genetic in origin or infective diseases [1]. It is common in Asia and oriental countries. Worldwide annual incidence of disease is $1.2-2.6$ cases/million [1] [3]. Women are affected in $80 \%-90 \%$ of cases with age of onset below 40 years [1] [4]. TA does not worsen or improve with pregnancy, but has adverse effect on pregnancy in the form of superimposed preeclampsia, abortion, intrauterine fetal death, intrauterine growth restriction, abruption and congestive heart failure [5] [6]. Because the disease is common in women of childbearing age, management of pregnancy in these patients becomes an important issue; however optimal management for pregnant patients with this disease has not yet been established. Due to the manifold cardiovascular complications that can occur in the course of the disease, management of pregnancies in TA patients is a challenge for the clinician. An interdisciplinary collaboration of obstetrician, rheumatologist, cardiologist and the anaesthetist is necessary to improve maternal and fetal prognosis [7]. This was the first reported case of TA in pregnancy in Hasan Sadikin Hospital with superimposed preeclampsia and pulmonary hypertension.

\section{CASE}

A female patient, G1P0A0, routinely come to the rheumatology clinic of Hasan Sadikin Hospital after diagnosed as TA since one year at age 19, and to the obstetric clinic when she was pregnant. During the first trimester her blood pressure was $160 / 90 \mathrm{mmHg}$ on the right arm and $90 / 60 \mathrm{mmHg}$ on the left arm. On the second trimester her blood pressure was $180 / 90 \mathrm{mmHg}$ on the right arm and $80 / 60 \mathrm{mmHg}$ on the left arm. At delivery her blood pressure was 200/100 on the right arm and 140/100 on the left; right hand pulse $120 \mathrm{x} / \mathrm{m}$, left hand pulse 113 $\mathrm{x} / \mathrm{m}$, respiration $20 \mathrm{x}$, temperature $36^{\circ} \mathrm{C}$. Thoracal examination showed symmetric form and movement, ronchi $-/-$, wheezing $-/-$. Other physical examination 
was in normal limits.

Laboratory values showed elevated C-reactive protein $6.8 \mathrm{mg} / \mathrm{dL}$, hemoglobin $10.5 \mathrm{~g} / \mathrm{dL}$, hematocrit $35 \%$, leukocyte count $12,400 / \mathrm{mm}^{3}$, platelets $272,000 / \mathrm{mm}^{3}$, MCV 78.3 fL, MCH 23.4 pg, MCHC 29.9\%, LED $36 \mathrm{~mm} / \mathrm{Hr}$, protein +2, ureum $18 \mathrm{mmol} / \mathrm{L}$, creatinine $0.68 \mathrm{mmol} / \mathrm{L}$, sodium $138 \mathrm{mmol} / \mathrm{L}$, potassium 4.1 $\mathrm{mmol} / \mathrm{L}$, calcium $4.72 \mathrm{mmol} / \mathrm{L}$, glucose $74 \mathrm{mg} / \mathrm{dL}$, GOT $16 \mathrm{U} / \mathrm{L}$, GPT $19 \mathrm{U} / \mathrm{L}$. In normal pregnancy, laboratory value in second trimester showed that C-reactive protein range 0.4 - $20.3 \mathrm{mg} / \mathrm{dL}$, hemoglobin 9.7 - $14.8 \mathrm{~g} / \mathrm{dL}$, hematocrit $30.0 \%$ $39.0 \%$, leukocyte count $5700-14,800 / \mathrm{mm}^{3}$, platelets $155,000-409,000 / \mathrm{mm}^{3}$, MCV 82 - $97 \mathrm{fL}, \mathrm{MCH} 30$ - 33 pg, ureum 3 - $13 \mathrm{mmol} / \mathrm{L}$, creatinine 0.4 - 0.8 $\mathrm{mmol} / \mathrm{L}$, sodium $129-148 \mathrm{mmol} / \mathrm{L}$, potassium 3.3 - $5.0 \mathrm{mmol} / \mathrm{L}$, calcium 4.4 $5.0 \mathrm{mmol} / \mathrm{L}[8]$.

Angiographic examination showed a little enlargement of aorta ascendent, narrowing of aorta descendent at 8 vertebra thoracal, no abnormalities on the arcus aorta and abdominal aorta and its branches (Figure 1). All these directed to type IIb Takayasu Arteritis.

Thorax rontgen examination showed cardiomegaly. Echocardiography on 20 21 weeks gestation showed normal function of global systolic and segmental LV, left ventricle ejection fraction 55\%, LVH “concentric" with diastolic dysfunction (relaxation disorders), moderate AR e.c. RCC calcification and $\mathrm{PH}$ was in accordance with heart disease hypertension and pulmonal hypertension.

The Ultrasound examination on the second trimester of gestation was to find out the detailed anatomic scan of the fetus, Doppler velocimetry of umbilical artery, median artery cerebry, uterine artery and fetal echocardiography (Figure $2)$. The results showed normal conditions.

The ultrasound examination at 36 - 37 weeks gestation shoed 2066 g estimated weight (symmetric IUGR). Doppler of the umbilical artery showed a resistant index (RI) of 0.49 , pulsatility index (PI) 0.70 with a positive end diastolic floe (EDF). Doppler of the median cerebry media artery showed a resistance index (RI) of 0.72, pulsatility index (PI) 1.26 . Amniotic Fluid Index $11.43 \mathrm{~cm}$, placenta corpus anterior (Figure 3 ).

The pregnancy was tightly controlled in our clinic. During the first trimester she got methylprednisolone $1 \times 4 \mathrm{mg}$, Azathioprin $1 \times 50 \mathrm{mg}$, folic acid $1 \times 1$ $\mathrm{mg}$. On the second trimester she got additional therapy with calcium $1000 \mathrm{mg}$, multivitamine $1 \mathrm{x} /$ day, Methyldopa $3 \times 250 \mathrm{mg}$, and acetylsalicylic acid $1 \times 80$ $\mathrm{mg}$. She was scheduled for a Caesarean section at term pregnancy.

\section{Discussions}

TA was first described in 1908 by the Japanese ophthalmologist Mikito Takayasu. It has variable geographical distribution with the greatest prevalence in Asians, especially Japan [5] [6]. Women are affected in $80 \%-90 \%$ of cases with a mean age of presentation in the second and third decade of life [1] [4], reflected in a synonym for TA as "young female arteritis". TA has higher incidence during the childbearing years and is usually detected on examination by decreased 


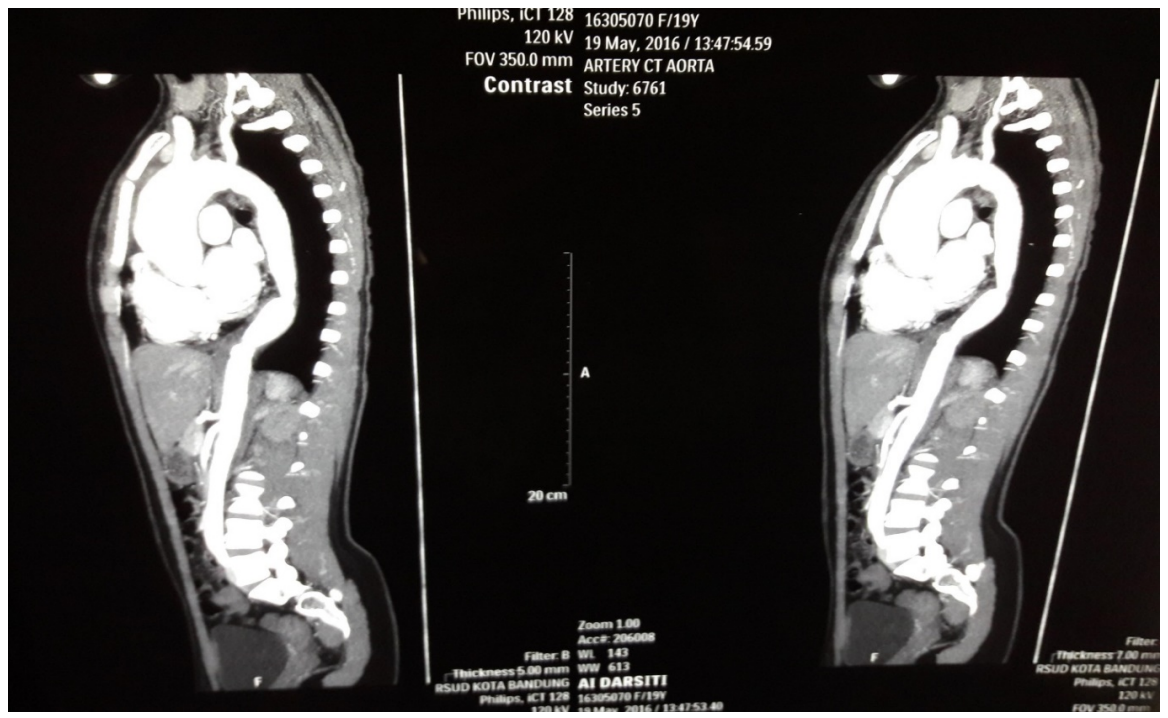

Figure 1. Angiographic images of a little enlargement of aorta ascendent and narrowing of aorta descendent at 8 thoracal vertebra.
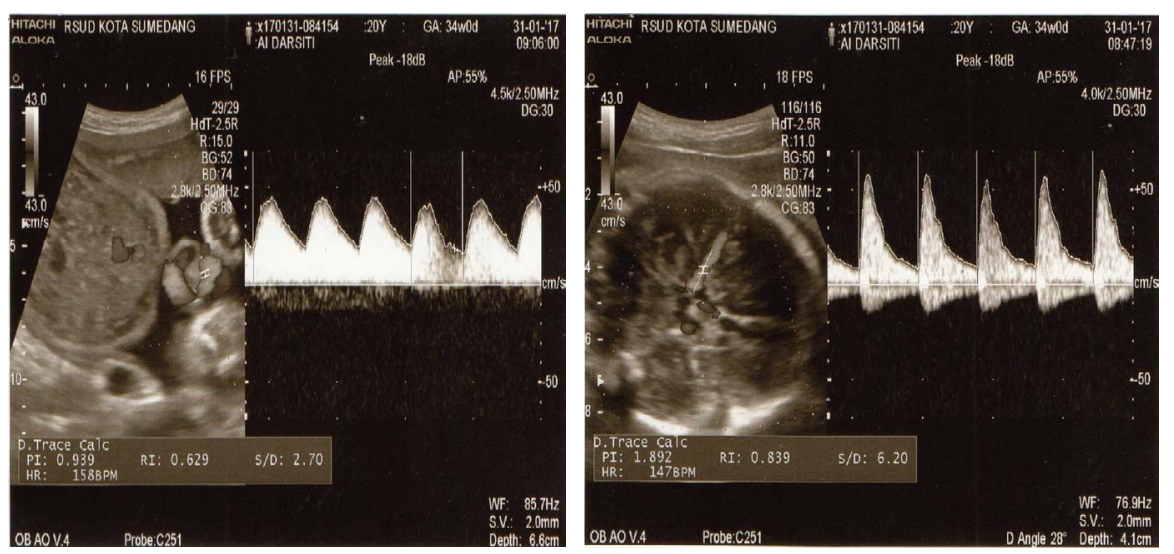

Figure 2. Doppler umbilical artery and median artery cerebry at the second trimester.
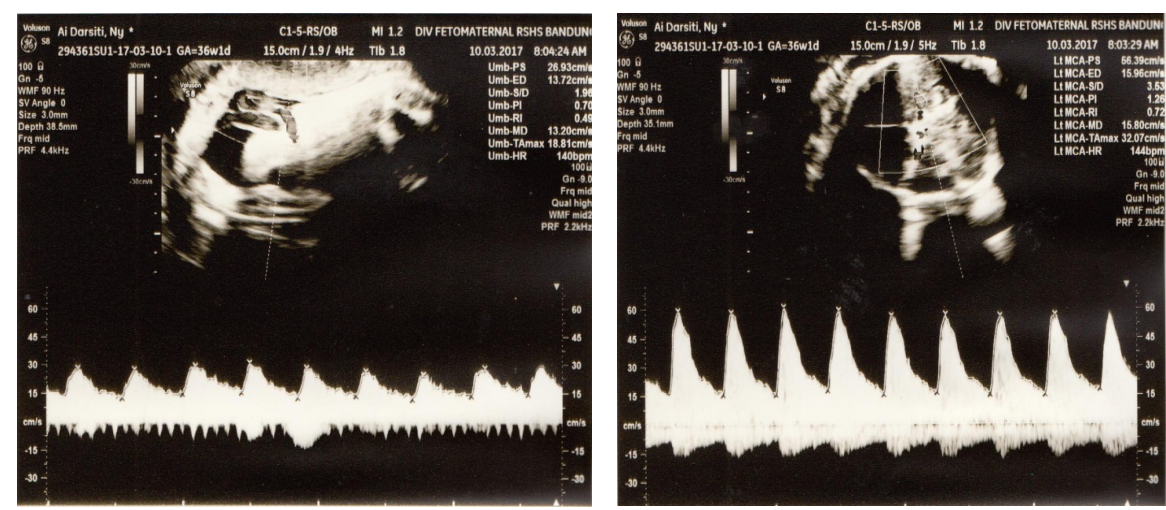

Figure 3. Doppler of umbilical artery and median artery cerebry at third trimester.

or absent peripheral pulses, discrepancies of blood pressure between the upper and lower extremities, and by the presence of arterial bruits. The maternal risk of pregnancy in association with TA is mainly attributed to the arterial hyperten- 
sion, heart failure and cerebral vascular accidents. The major risk for the fetus is intrauterine growth restriction and in utero fetal demise. The risk of fetal death is greatest in the third trimester, especially in those with uncontrolled hypertension [5] [6].

Because the incidence of Takayasu arteritis during childbearing years is relatively high, pregnancy is common among patients with TA. However, pregnancy complicated with the disease can be life-threatening and the management of which is challenging. The increased intravascular volume due to physiological change during pregnancy can impair maternal hemodynamics and exacerbate the pre-existing hypertension, aortic regurgitation, cerebrovascular accident, and congestive heart failure. The preexisting hypertension is often more severe especially in late pregnancy and often associated with intrauterine growth restriction, fetal hemorrhage, and maternal heart failure [7] [8].

The cause is unknown, but it seems to be related to autoimmunity, sex hormones (more common in young females), and genetics (demonstrated by the predisposition of the human leukocyte antigen HLA A9, A10, B5, BW40, BW52, DQW1, DR2, DR4, DR7, DW3 and DW12) [2] [8].

In 1990, the American College of Rheumatology proposed six diagnostic criteria $[4]$ :

1) Age at disease onset 40 years or younger

2) Claudication of the extremities

3) Decreased pulsation of one or both brachial arteries

4) Difference of at least $10 \mathrm{~mm} \mathrm{Hg}$ in systolic blood pressure between the arms

5) Bruit over one or both subclavian arteries or the abdominal aorta

6) Arteriographic narrowing or occlusion of the entire aorta, its primary branches, or large arteries in the proximal upper or lower extremities, not due to arteriosclerosis, fibromuscular dysplasia, or other causes at least three of them are required for classifying a patient as having $\mathrm{TA}$.

Angiographic classification of Takayasu's arteritis Classification is based on the vessels involved in the inflammatory process as seen on angiography. Type I includes Branches of the aortic arch. Type IIa includes Ascending aorta, aortic arch, and branches of the aortic arch. Type IIb includes Ascending aorta, aortic arch, and its branches and thoracic descending aorta. Type III includes Thoracic descending aorta, abdominal aorta, and/or renal arteries. Type IV includes abdominal aorta and/or renal arteries. Type V includes Features of types IIb and IV [5].

Disease progression typically occurs in various stages from acute inflammatory arteritis to lymphocytic infiltration, intimal thickening, elastic tissue destruction, fibrosis and patchy luminal narrowing of arteries. Depends on presence or absence of four major complications such as hypertension, retinopathy, aneurysm and aortic insufficiency, it can be classified into four stages. In stage 1, None of these complications were present. Stage 2a, patients had only one of this complication. Stage $2 b$, patients had one of these complications but in the severe 
form. Stage 3, when more than one complication was present [1].

Fertility is not adversely affected, pregnancy per se does not appear to exacerbate the disease, but management of hypertension is essential. The maternal risk of pregnancy in association with TA is mainly attributed to the arterial hypertension, heart failure and cerebral vascular accidents. In patients with Takayasu's arteritis, pregnancy acts as a burden to the already compromised circulatory system. Uncontrolled hypertension, cerebrovascular ischemic, near complete occlusion of systemic and pulmonary arteries and congestive cardiac failure are known life threatening complications during late pregnancy and labor. More specific symptoms suggestive of circulatory insufficiency such as vision disturbances, myocardial ischemic chest pain and stroke appear [9] [10].

BP control is of importance as increase can cause rupture of aneurysms and falls in BP can lead to cerebral ischemia in the mother. Most patients benefit from invasive BP monitoring or by monitoring peripheral BPs in multiple extremities as upper extremity pulses may be absent. Peripheral BP monitoring may not be accurate, complicating the treatment of hypertension in these patients [1]. Classically the disease may have a triphasic course. In the initial active phase of the disease patient presents with vague constitutional symptoms such as malaise, weight loss, fever, myalgias and arthralgias, as a result of which diagnosis may be missed as can be noted in our case. This phase is generally associated with increase in C-reactive protein and or erythrocyte sedimentation rate i.e. acute phase reactants. This progresses to a second phase with symptoms of cerebral, visceral or extremity ischemia. This in due course culminates in a final 'burnt-out' quiescent phase of fibrosis. The severity and progression of vessel involvement are extreme variable and these 'typical' symptoms are seen in only 33 per cent of all patients [6].

Gasch et al. reported the rate of pregnancy induced hypertension/preeclampsia as $39 \%$ in their study of 137 pregnant women. Furthermore, they stated that although heart failure had developed in 5 of their cases, no maternal deaths had occurred. In the evaluation of 115 cases from different centers associated with the problems in the fetus due to ischemic and destructive reasons, the abortus rate was $15.6 \%$, the premature birth rate was $9.5 \%$, and the IUGR rate was $17 \%$, and neonatal death was reported in only 1 case. The rate of caesarean section was $26 \%$. Twenty of the caesarian indications were maternal causes and 17 of these were maternal hypertension/preeclampsia and other vascular diseases [11]. The Hypertension may be due to decreased elasticity and narrowing of aorta and abnormal function of carotid and aortic sinus baroreceptor.

Anti hypertensive drugs and antiplatelets can be started as per need, as was in the present case. Anti hypertensive agents that are safely used with proven success in pregnancy are labetolol, hydralazine, and alpha methyldopa. TA may respond symptomatically to corticosteroid therapy (first line drugs) at a dose of 1 $2 \mathrm{mg} / \mathrm{kg} /$ bodyweight for 4 weeks followed by slow tapering. In another case with Immunosuppressive therapy (methyl prednisolone $40 \mathrm{mg} / \mathrm{d}$ ) was started. However, chronic use of corticosteroids could lead to suppression of adrenal gland 
activity with inadequate release of endogenous corticosteroids in moments of stress, such as surgeries Also immune suppressors including azathioprine are used [12].

As per European League Against Rheumatism (EULAR), initial high doses of glucocorticoids were used for the remission of the disease and an immunosuppressive agent is used as an adjunctive therapy. EULAR recommends the starting dose of glucocorticoids $1 \mathrm{mg} / \mathrm{kg}$ body weight for four weeks and then to taper them off [6]. The patient was given various therapy including hypertension control, i.e. Alpha methyldopa, immunosuppression methylprednisolone $1 \times 4 \mathrm{mg}$, Azathioprin $1 \times 50 \mathrm{mg}$, multivitamin and antiplatelet (Acetylsalicylic acid) $1 \times$ $80 \mathrm{mg}$.

The mode of delivery in patients with TA is determined by the hemodynamic status of the mother and for obstetrical indications. Vaginal delivery could be indicated for patients in groups I and II as long as epidural analgesia is used for pain relief, and delivery is abbreviated by the use of forceps especially in hypertensive patients. In groups II b and III, one should prefer caesarean section, since the increased blood volume and blood pressure observed during uterine contractions as well as the increased cardiac output observed during labor may lead to cardiac decompensation. Hypertension in the second stage of labor is a risk factor for cerebral hemorrhage; shortening this stage by use of low forceps delivery or vacuum extraction appears to be a reasonable solution [9] [12].

The patient was scheduled for cesarean section at term gestation age due to pulmonary hypertension, but as 36 weeks she got parturient and emergencies caesarean section was done with epidural anaesthesia by bupivacaine followed by intensive care afterwards. The baby was born with 2180 grams birth weight, body length $44 \mathrm{~cm}$, Apgar 1' 7, 5' 9. Fetal and maternal conditions were good.

Regional anesthesia is as safe as an awake and communicating patient and is the best clinical neurologic monitor. However, the associated sympathetic blockade-induced hypotension may compromise the regional circulation. The graded blockade with epidural anesthesia not only avoids precipitous falls in blood pressure, but also lowers the rate of thrombosis. Although sympatholysis is avoided with the use of general anesthesia, sophisticated monitoring of the cerebral function is needed as it may be associated with hypertensive episode and consequent cerebral/cardiac events [14].

Overall maternal mortality rate of women with Takayasu's arteritis is $48 \%$ and further pregnancy is not advised in patients with group IIb and III disease. Risk is greatest during III trimester and perinatal period. Blood pressure changes during labor are greater in patients with Takayasu arteritis than in healthy patients, hence reasons for caesarean section depend on obstetric indications as well on severity of the disease. State of Takayasu in early pregnancy and magnitude of blood pressure elevation in late gestation are the most critical factors in determining the management and main aim of treatment is suppression of inflammation and preservation of vascular competence. Although proper antenatal and intrapartum management with a multidisciplinary approach, the adverse 
pregnancy outcomes are still rather high, however, a successful outcome could be expected if judicious medication and a multidisciplinary approach as well as a timely admission are instituted. The cornerstone of management is control of blood pressure, which plays an important role in pregnancy outcome [8] [15].

\section{Conclusion}

The management of TA in pregnancy is still a challenge. A multidisciplinary team involving obstetrician, cardiologist, rheumatologist and anaesthetist is absolutely needed to get an optimal development of the pregnancy. The risk of complication on the mother and fetus might occur anytime. Adequately controlled blood pressure and fetal monitoring might result for better outcome. Birth delivery (pervaginam or perabdominal) is still a problem according to obstetrical condition, general condition of the mother and other additional factors. Careful assessment, treatment of TA complication, regular antenatal follow-up improve maternal and fetal outcome.

\section{Conflicts of Interest}

Authors declare no conflict of interest. The patient had given her consent to authors for the case report to be published.

\section{References}

[1] Nalini, S. and Santa, S.A. (2015) Takayasu Arteritis with Bilateral Renal Artery Stenosis and Left Subclavian Artery Stenosis in Pregnancy. Journal of Clinical and Diagnostic Research, 9, 7-8.

[2] Leal, P.D., Silveira, F.F., Sadatsune, E.J., Clivatti, J. and Yamashita, A.M. (2011) Takayasus's Arteritis in Pregnancy. Case Report and Literature Review. Brazilian Journal of Anesthesiology, 61, 479-485. https://doi.org/10.1016/S0034-7094(11)70056-3

[3] Salhi, S., Ameur, I., Abdallah, M.B., Hajjaji, A. and Haddad, A. (2016) Takayasu's Arteritis and Pregnancy: A Case Report and Review of Literature. Gynecology \& Obstetrics, 6, 1-2. https://doi.org/10.4172/2161-0932.1000399

[4] Hauenstein, E., Frank, H., Bauer, J.S., Schneider, K. and Fischer, T. (2010) Takayasu's Arteritis in Pregnancy: Review of Literature and Discussion. Journal of Perinatal Medicine, 38, 55-62. https://doi.org/10.1515/jpm.2009.120

[5] Waanbah, B.A., Rathore, S., Benjamin, S.J. and Kingsbury, S. (2016) Pregnancy with Takayasu's Arteritis. Indian Journal of Obstetrics and Gynecology Research, 3, 422-425.

[6] Singh, S., Kohli, U.A., Biswas, M. and Singh, M. (2016) A Rare Case of Takayasu's Arteritis in Pregnancy. International Journal of Reproduction, Contraception, $\mathrm{Ob}$ stetrics and Gynecology, 5, 552-555. https://doi.org/10.18203/2320-1770.ijrcog20160411

[7] Gasch, O., Vidarell, A. and Pujol, R. (2009) Takayasu Arteritis and Pregnancy from the Point of View of the Internist. The Journal of Rheumatology, 36, 1554-1555. https://doi.org/10.3899/jrheum.080362

[8] Queenan, J.T., Hobbins, J.C. and Spong, C.Y. (2010) Protocol for High-Risk Pregnancy: An Evidence-Based Approach. 5th Edition, Blackwell Science Ltd., Oxford. 
[9] Rujiwetpongstorn, J. and Yanase, Y. (2013) Takayasu Disease in Twin Pregnancy: A Case Report. Journal of the Medical Association of Thailand, 96, 1508-1511.

[10] Khandelwal, R., et al. (2016) Successful Pregnancy Outcome in a Case of Takayasu's Arteritis with Recurrent Pregnancy Loss with Low Dose Heparin. International Journal of Reproduction, Contraception, Obstetrics and Gynecology, 5, 3210-3212. https://doi.org/10.18203/2320-1770.ijrcog20163014

[11] Chhabra, S. and Coelho, K. (2009) An Unusual Case of Pregnancy with Severe Takayasu's Arteritis. Bombay Hospital Journal, 51, 526-527.

[12] Keskin, H.L., Turgut, O., Üstüner, I., Tan, S. and Avflar, A.F. (2010) Successful Maternal and Fetal Outcome in a Pregnancy with Type V Takayasu's Arteritis. Perinatal Journal, 18, 105-108.

[13] Marwah, S., Rajput, M., Mohindra, R., Gaikwad, H.S., Sharma, M. and Topden, S.R. (2017) Case Report Takayasu's Arteritis in Pregnancy: A Rare Case Report from a Tertiary Care Infirmary in India. Case Reports in Obstetrics and Gynecology, 2017, Article ID: 2403451. https://doi.org/10.1155/2017/2403451

[14] Tiwari, A.K., Tomar, G.S., Chadha, M. and Kapoor, C.M. (2011) Takayasu's Arteritis: Anesthetic Significance and Management of a Patient for Cesarean Section Using the Epidural Volume Extension Technique. Anesthesia: Essays and Researches, 5, 98-101. https://doi.org/10.4103/0259-1162.84184

[15] Oner, F.A., Aydın, S.Z. and Direskeneli, H. (2015) Recent Advances in Takayasu's Arteritis. European Journal of Rheumatology, 1, 24-30.

https://doi.org/10.5152/eurjrheumatol.2015.0060 